\title{
ÍNDICES DE EFICIÊNCIA DE VARIEDADES LOCAIS E MELHORADAS DE MILHO AO FÓSFORO ${ }^{(1)}$
}

\author{
CYNTHIA TORRES DE TOLEDO MACHADO ${ }^{(2)}$; ANGELA MARIA \\ CANGIANI FURLANI ${ }^{(3,5)}$; ALTAIR TOLEDO MACHADO ${ }^{(4)}$
}

\begin{abstract}
RESUMO
Avaliaram-se dez variedades locais e melhoradas de milho (Zea mays L.) a fim de verificar sua eficiência ao fósforo (P) em solução nutritiva e em campo. Em solução nutritiva, o experimento foi realizado no Instituto Agronômico, Campinas (SP), durante 1995-1996; o delineamento adotado foi o de em blocos ao acaso, com cinco repetições. Os tratamentos, dispostos em fatorial, constituíram-se de três concentrações de $\mathrm{P}\left(0,0645 ; 0,129\right.$ e $\left.0,258 \mathrm{mmol} . \mathrm{L}^{-1}\right)$ e dez variedades de milho. Em campo, o experimento foi instalado na Embrapa Agrobiologia, em Seropédica (RJ), durante 1998-1999, em blocos ao acaso, com seis repetições, utilizando-se a dose de $44 \mathrm{~kg} \cdot \mathrm{ha}^{-1} \mathrm{de} \mathrm{P}\left(100 \mathrm{~kg} \cdot \mathrm{ha}^{-1} \mathrm{de} \mathrm{P}_{2} \mathrm{O}_{5}\right)$ e as mesmas variedades de milho utilizadas em solução nutritiva: Caiano de Sobrália, Carioca, Antigo Maya, Catetão, Pedra Dourada, Nitrodente, Sol da Manhã (BRS Sol da Manhã), BR 105, BR 106 e BR 107. Determinaram-se a produção de matéria seca e/ou de grãos, conteúdo de $\mathrm{P}$ e índices de eficiência nas plantas de ambos os experimentos. As variedades Nitrodente e BR 106 acumularam mais matéria seca na parte aérea em solução nutritiva e apresentaram maiores produções de grãos e índices de eficiência em campo. Catetão, a menos produtiva em campo, mostrou uma das menores produções de matéria seca da parte aérea e de raízes em solução nutritiva. Os resultados para Pedra Dourada, BR 105, BR 107, Antigo Maya e Sol da Manhã foram intermediários e, também, comparáveis entre os ensaios de campo e em solução nutritiva. Foram exceções as variedades Carioca e Caiano, com as menores produções de matéria seca em solução nutritiva e as mais produtivas em campo.

Palavras-chave: Zea mays L., variabilidade genética, solução nutritiva, nutrição fosfatada.
\end{abstract}

\section{ABSTRACT \\ PHOSPHORUS EFFICIENCY INDEX OF LOCAL AND IMPROVED CORN VARIETIES}

Local and improved corn varieties were evaluated to phosphorus (P) efficiency in nutrient solution and field. In nutrient solution, the experiment was set up at Instituto Agronômico, Campinas, São Paulo State, Brazil, during 1995-1996, in a randomized complete block design, with 5 replicates, in a factorial with three P concentrations $\left(0.0645 ; 0.129\right.$ e 0.258 mmol. $\left.\mathrm{L}^{-1}\right)$ and ten maize varieties. In the field, the experiment was set up at the research center of Embrapa Agrobiologia, Seropédica, Rio de Janeiro State, Brazil, during 1998-1999, using a randomized complete block design, with 6 replicates, and $44 \mathrm{~kg} \cdot \mathrm{ha}^{-1}$ of $\mathrm{P}\left(100 \mathrm{~kg} \cdot \mathrm{ha}^{-1}\right.$ of $\left.\mathrm{P}_{2} \mathrm{O}_{5}\right)$. The varieties used were Caiano de Sobrália, Carioca, Antigo Maya, Catetão, Pedra Dourada, Nitrodente, Sol da Manhã (BRS Sol da Manhã), BR 105, BR 106 and BR 107. Dry matter and, or grain yield, $P$ content and $P$ efficiency index were determined in plants of both experiments. The varieties Nitrodente and BR 106 showed the highest shoot dry matter in nutrient

( ${ }^{1}$ ) Parte da tese de Doutorado em Agronomia, Área Ciência do Solo, da primeira autora, apresentada à Universidade Federal Rural do Rio de Janeiro, Seropédica (RJ). Trabalho realizado com apoio financeiro da CAPES, FAPESP e EMBRAPA. Recebido para publicação em 18 de junho e aceito em 13 de novembro de 2001.

$\left({ }^{2}\right)$ Com bolsa da CAPES.

(3) Centro de Solos e Recursos Agroambientais, Instituto Agronômico (IAC), Caixa Postal 28, 13001-970 Campinas (SP).

$\left({ }^{4}\right)$ Embrapa Agrobiologia, Caixa Postal 74505, 23851-970 Seropédica (RJ).

(5) Com bolsa de produtividade em pesquisa do CNPq. 
solution and the highest grain yield and efficiency index at field conditions. Catetão, with the lowest grain yield in field, showed also low shoot and root dry matter production in nutrient solution. The results in field and nutrient solution were also comparable for Pedra Dourada, BR 105, BR 107, Antigo Maya and Sol da Manhã (intermediary production). The exceptions were the varieties Carioca and Caiano, with inferior performance in nutrient solution and high grain yields in the field.

Key words: Zea mays L., genetic variability, nutrient solution, phosphorus nutrition.

\section{INTRODUÇÃO}

A identificação de cultivares de milho eficientes ao fósforo (P), bem como o conhecimento dos mecanismos responsáveis pela eficiência são de extrema importância face à demanda de rendimento mais elevado em solos de baixa fertilidade natural e redução no uso de fertilizantes.

A eficiência é definida como a capacidade de determinado genótipo em adquirir o nutriente para incorporá-lo e utilizá-lo na produção de biomassa ou material vegetal de rendimento econômico (BLAIR, 1993), como os grãos, no caso específico dos cereais. Os critérios ou definições de eficiência são vários e, geralmente, dividem-se entre os que enfatizam a produtividade e aqueles que enfatizam o requerimento interno do nutriente na planta (GouRLEY et al., 1994), dependentes das características morfológicas, bioquímicas e fisiológicas dos vegetais.

Com relação aos conceitos que enfocam parâmetros de produtividade, a eficiência nutricional pode ser definida como a capacidade da planta em produzir alto rendimento em um meio que possua características que afetem diretamente a produção-padrão. $\mathrm{O}$ requerimento ou nível crítico externo, definido como a quantidade necessária de nutriente no meio de cultivo para atingir determinada porcentagem do rendimento máximo (Ozanne, 1976 citado por BlaIR, 1993), da mesma forma se enquadra nos conceitos que enfatizam a produtividade. Outras definições de eficiência nutricional, também denominadas "eficiência agronômica", incluem a produção da parte aérea ou do produto colhido por unidade do nutriente aplicado (GOURLEY et al., 1994).

A eficiência nutricional enfatizando a utilização é geralmente definida como a biomassa total produzida pela planta por unidade de nutriente absorvido, que é equivalente ao inverso da concentração do nutriente na planta inteira. Essa relação é denominada, freqüentemente, "relação de eficiência nutricional" (GOURLEY et al., 1994) e tem sido usada para descrever o requerimento interno de nutrientes de várias espécies agronômicas. SiddiQI e Glass (1981) argumentaram que o inverso da concentração de nutrientes não expressa o crescimento ou rendimento da planta. Esses autores sugeriram que uma medida mais apropriada de eficiência nutricional seria o produto do rendimento pelo inverso da concentração de nutrien- tes, o que foi denominado "eficiência de utilização". Quando se relacionam os parâmetros de concentração com a massa produzida, além da determinação dos componentes da eficiência de utilização, podem também ser claramente deduzidos os níveis de deficiência, os ótimos e os de consumo de luxo, desde que se relacionem os aumentos nas quantidades de nutriente acumulado com aqueles no crescimento e rendimento do vegetal (ISRAEL e RUFTY, 1988).

Índices, que variam basicamente apenas na denominação dos componentes, têm sido propostos para caracterizar genótipos quanto à eficiência nutricional, quantificando a absorção, translocação e utilização dos nutrientes e, também, o uso do adubo aplicado (Fox, 1978; Moll et al., 1982; BlaIR, 1993; GouRley et al., 1993, 1994; Baligar e FAgeria, 1997). A determinação de tais índices para o P é interessante em genótipos de milho, fazendo-se necessária para elucidar os mecanismos determinantes da eficiência a esse nutriente, podendo ser utilizados como critério de seleção em tais materiais.

A avaliação de genótipos vegetais para eficiência nutricional em solução nutritiva, em plantas com até 30 dias de idade, tem sido vantajosa e de grande utilidade, pois permite controlar rigorosamente os fatores de variação e da pressão de seleção, seja por deficiência ou excesso de determinado nutriente. Nessas condições, têm sido bem sucedidas as análises de eficiência na absorção e utilização de fósforo em milho e outras espécies, quando se pretende conhecer a variabilidade genotípica em características intrínsecas da planta, como o requerimento interno para crescimento (produção de matéria seca), a morfologia das raízes (massa, comprimento, raio, volume) e as possíveis relações com a variabilidade na cinética da absorção iônica (BREEZE et al., 1984; FURLANI et al., 1985; Alves et al., 1998; CiARelli et al., 1998). Para estudos exploratórios de herdabilidade em gerações $F_{1}$ derivadas de parentais selecionados, utilizam-se plantas jovens cultivadas em solução nutritiva (FURLANI et al., 1987, 1998).

Faltam, entretanto, estudos comparativos com resultados obtidos em campo para melhor compreender e avaliar o sucesso do emprego dessa técnica na seleção de genótipos de milho para eficiência na absorção e utilização de fósforo. Assim, realizou-se este trabalho com o objetivo de avaliar variedades de 
milho - locais e melhoradas - quanto à eficiência de absorção, translocação e utilização de fósforo em solução nutritiva e em campo, comparando-se os resultados dos dois ambientes.

\section{MATERIAL E MÉTODOS}

Utilizaram-se dez variedades de polinização livre, separadas entre "locais" e "melhoradas" em função de seu processo de seleção e adaptação. As locais são aquelas que vêm sendo desenvolvidas e cultivadas por agricultores por um período mínimo de dez anos e as melhoradas ou selecionadas, desenvolvidas por instituições de pesquisa. A escolha das variedades teve como base os resultados de ensaios de competição em locais com baixos níveis de $\mathrm{P}$ em seis Estados brasileiros (MACHADO et al., 1998) e um estudo anterior de avaliação da eficiência de utilização e resposta ao fósforo (MACHADO, 1995), nos quais se observaram diferenças entre essas variedades. Caiano de Sobrália, Carioca, Antigo Maya, Catetão e Pedra Dourada foram as variedades locais; Nitrodente, Sol da Manhã (BRS Sol da Manhã), BR 105, BR 106 e BR 107 as variedades melhoradas. Sua caracterização e origem encontram-se em MACHADO (2000).

\subsection{Avaliação de variedades de milho para eficiência ao fósforo em solução nutritiva}

Este ensaio foi realizado em casa de vegetação, no Centro Experimental do Instituto Agronômico, Campinas (SP), no período de 1995-1996, utilizando-se a técnica de seleção de plantas jovens em solução nutritiva, proposta por FURLANI e FURLANI (1988). O delineamento experimental adotado foi o de blocos ao acaso em fatorial, com cinco repetições. Os tratamentos constituíram-se de três concentrações de $\mathrm{P}$ na solução nutritiva adicionados na forma de $\mathrm{KH}_{2} \mathrm{PO}_{4}$ : 2, 4 e $8 \mathrm{mg}$. $\mathrm{L}^{-1}$ de $\mathrm{P}$ (equivalentes a 0,0645; 0,129 e $\left.0,258 \mathrm{mmol} . \mathrm{L}^{-1}\right)$, e das dez variedades de milho descritas anteriormente.

As sementes foram germinadas em rolos de papel de germinação, e as plântulas, com dez dias de idade, transplantadas em número de três por vaso. Procedeu-se à determinação do conteúdo de $\mathrm{P}$ em amostras das sementes, cujos valores médios (por 100 sementes) foram 133, 133, 187, 160, 147, 227, 107, 133, 187 e 213 mg, respectivamente, para Caiano de Sobrália, Carioca, Antigo Maya, Catetão, Pedra Dourada, Nitrodente, Sol da Manhã, BR 105, BR 106 e BR 107. Os vasos com capacidade de $3 \mathrm{~L}$ receberam solução, cuja composição, descrita em FURLANI e FuRLANI (1988), constituiu-se em mg. $\mathrm{L}^{-1}$ de: $\mathrm{Ca}=151$; $\mathrm{K}=141 ; \mathrm{Mg}=17 ; \mathrm{N}-\mathrm{NO}_{3}=138 ; \mathrm{N}^{-\mathrm{NH}_{4}}=20 ; \mathrm{S}=56$; $\mathrm{Cl}=33 ; \mathrm{Fe}=3,6 ; \mathrm{Mn}=0,5 ; \mathrm{B}=0,27 ; \mathrm{Zn}=0,15$;
$\mathrm{Cu}=0,04 ; \mathrm{Mo}=0,08$, nas formas de: $\mathrm{Ca}\left(\mathrm{NO}_{3}\right)_{2} \cdot 4 \mathrm{H}_{2} \mathrm{O}$; $\mathrm{NH}_{4} \mathrm{NO}_{3} ; \mathrm{KCl} ; \mathrm{K}_{2} \mathrm{SO}_{4} ; \mathrm{KNO}_{3} ; \mathrm{MgSO}_{4} .7 \mathrm{H}_{2} \mathrm{O} ; \mathrm{Fe}-$ HEDTA (preparado com HEDTA e $\mathrm{FeSO}_{4} .7 \mathrm{H}_{2} \mathrm{O}$ ); $\mathrm{MnCl}_{2} .4 \mathrm{H}_{2} \mathrm{O} ; \mathrm{H}_{3} \mathrm{BO}_{3} ; \mathrm{ZnSO}_{4} .7 \mathrm{H}_{2} \mathrm{O} ; \mathrm{CuSO}_{4} .5 \mathrm{H}_{2} \mathrm{O}$ e $\mathrm{Na}_{2} \mathrm{MoO}_{4} \cdot 2 \mathrm{H}_{2} \mathrm{O}$. O pH inicial da solução foi 5,0. A solução foi continuamente arejada durante o experimento, não sendo renovada, e o volume do vaso foi completado com água destilada em dias alternados.

Durante o período de crescimento das plantas, as médias das temperaturas máxima e mínima na casa de vegetação foram, respectivamente, $36 \pm 5{ }^{\circ} \mathrm{C}$ e $19 \pm 1{ }^{\circ} \mathrm{C}$. As plantas foram colhidas com 25 dias de idade (15 dias em solução nutritiva), lavadas em água destilada e separadas em parte aérea (folhas e colmos mais bainhas) e raízes. A seguir, foram secas em estufa, pesadas para a determinação da massa de matéria seca (MS), moídas e submetidas à análise química de P pelo método do vanado-molibdato de amônio. Calcularam-se, também, as seguintes variáveis: (1) relação raiz/parte aérea de MS; (2) conteúdo de P na MS da parte aérea e das raízes; (3) relação parte aérea/raízes do conteúdo de P; (4) índice de eficiência de utilização (IE), de acordo com SIDDIQI e Glass (1981): IE = (MS $)^{2} /$ conteúdo total de P.

\subsection{Avaliação de variedades de milho para eficiência ao fósforo em campo}

Realizou-se este experimento em condições de campo, solo ARGISSOLO (EMBRAPA, 1999) na área experimental da Embrapa Agrobiologia, em Seropédica, RJ. A análise química do solo, coletado na profundidade de $0-20 \mathrm{~cm}$, de acordo com o método da Embrapa (1997), revelou as seguintes características: $\mathrm{pH}$ (água) $=4,5 ; \mathrm{P}\left(\mathrm{mg} \cdot \mathrm{dm}^{-3}\right)=10 ; \mathrm{Al}, \mathrm{Ca}, \mathrm{Mg} \mathrm{e} \mathrm{K}$ $\left(\right.$ mmol $\left._{\mathrm{c}} \cdot \mathrm{dm}^{-3}\right)=3,0 ; 31,0 ; 9,0$ e 1,51. A dose de $\mathrm{P}$, aplicada na forma de superfosfato simples, foi de $44 \mathrm{~kg} \cdot \mathrm{ha}^{-1}$ (100 kg.ha- ${ }^{-1}$ de $\left.\mathrm{P}_{2} \mathrm{O}_{5}\right)$, definida em função do teor disponível no solo, da produtividade esperada e da resposta de produção de grãos de alguns desses materiais quando avaliados sob níveis crescentes de adubação fosfatada (MACHADO, 1995). Efetuouse a calagem, aplicando-se a dose de $600 \mathrm{~kg} \cdot \mathrm{ha}^{-1} \mathrm{de}$ calcário. Aplicaram-se $\mathrm{N}$ e $\mathrm{K}$ nas quantidades de $100 \mathrm{~kg} \cdot \mathrm{ha}^{-1}$ de N, na forma de uréia, sendo essa dose parcelada (1/3 no desbaste e o restante aplicado 10 dias depois) e $40 \mathrm{~kg} \cdot \mathrm{ha}^{-1}$ de $\mathrm{K}_{2} \mathrm{O}$, na forma de $\mathrm{KCl}$, aplicados no plantio. A calagem e a adubação foram feitas com base nos resultados da análise de solo e na recomendação para a cultura do milho no Estado do Rio de Janeiro (AlmeidA et al., 1988). O delineamento experimental adotado foi o de blocos ao acaso, com seis repetições, e a parcela experimental constituiu-se de 1 linha de $5 \mathrm{~m}$, com $1 \mathrm{~m}$ de espaçamento entre as 
linhas. O estande foi adequado para 50.000 plantas.ha ${ }^{-1}$ por desbaste realizado aos 27 dias após a semeadura. Ao final do ciclo, por ocasião da colheita - aproximadamente aos 130 dias após o plantio -, determinou-se a produção de matéria seca (MS) da parte aérea, compreendida pela MS de folhas e colmos (palha), MS de sabugos, produção de grãos, teores e conteúdos de $\mathrm{P}$ nessas partes.

Os índices de eficiência utilizados, calculados de acordo com Moll et al. (1982), foram: Pg/Ns: avalia o uso eficiente do fertilizante aplicado para produção de grãos - $\mathrm{kg}$ de grãos. $\mathrm{kg}^{-1}$ de $\mathrm{P}$ aplicado; $\mathbf{N p}$ /Ns: avalia a eficiência de absorção do nutriente pela planta - kg de P acumulado na planta. $\mathrm{kg}^{-1}$ de P aplicado; Pg/Np: avalia a eficiência de utilização do nutriente para a produção de grãos - $\mathrm{kg}$ de grãos. $\mathrm{kg}^{-1} \mathrm{de}$ $\mathrm{P}$ acumulado na planta; $\mathbf{P g} / \mathbf{N g}$ : avalia a produção de grãos por unidade do nutriente nos grãos - $\mathrm{kg}$ de grãos. $\mathrm{kg}^{-1}$ de $\mathrm{P}$ acumulado nos grãos; $\mathbf{N g} / \mathrm{Np}$ : avalia a fração do total do nutriente na planta que é translocado para os grãos - kg de P acumulado nos grãos. $\mathrm{kg}^{-1}$ de $\mathrm{P}$ acumulado na planta inteira, em que Pg: produção de grãos; Ns: quantidade de P suprido a partir do fertilizante fosfatado aplicado; Np: quantidade total de P na planta; Ng: quantidade de P nos grãos.

Os procedimentos estatísticos aplicados aos dados de ambos os experimentos, compreendendo análise da variância, testes de médias (Duncan) e correlações simples foram realizados com o uso do programa MSTAT-C (Michigan State University), versão 1989.

\section{RESULTADOS E DISCUSSÃO}

\subsection{Avaliação de variedades de milho para eficiência ao fósforo em solução nutritiva}

O aumento na concentração de P na solução promoveu acréscimos na produção de matéria seca da parte aérea até a dose de $8 \mathrm{mg}$. $\mathrm{L}^{-1}$ de $\mathrm{P}$; fato não observado para as raízes (Quadro 1).

Para a matéria seca da parte aérea, a variedade Nitrodente foi superior em todas as doses, e a Carioca, inferior. Verificaram-se diferenças estatísticas entre e dentro dos grupos de variedades locais e melhoradas; estas produziram quantidades significativamente maiores quando comparadas àquelas. Entre as melhoradas, a que apresentou melhor desempenho foi Nitrodente e entre as locais, Antigo Maya.

Para a produção de raízes a variedade Antigo Maya, seguida de Pedra Dourada, BR 106, BR 105 e Nitrodente foram superiores; verificaram-se, contudo, diferenças menores para a parte aérea. No nível de $\mathrm{P}$ mais baixo, Antigo Maya e Nitrodente apresentaram os maiores sistemas radiculares, e a variedade local Carioca, o menor. Nas médias de grupos, não houve diferença entre as variedades locais e as melhoradas, nem dentro do grupo das melhoradas. Entre as locais, Antigo Maya e Pedra Dourada produziram mais matéria seca de raízes.

As proporções de matéria seca e de P distribuídas entre as raízes e a parte aérea são fatores importantes na eficiência de absorção e utilização do P. Observouse que para todos os materiais a relação raiz/parte aérea de matéria seca foi maior na menor dose de $\mathrm{P}$, diminuindo à medida que houve acréscimo do nutriente na solução nutritiva. A relação raiz/parte aérea foi reduzida, em média, aproximadamente em $41 \%$, quando se aumentou a dose de $\mathrm{P}$ de 2 para $8 \mathrm{mg}$. $\mathrm{L}^{-1}$ (Quadro 1). Esse fato tem sido verificado freqüentemente (Alves et al., 1988; FÖHSE et al., 1988) para várias espécies vegetais e sugere que as raízes se tornam em drenos preferenciais de fotoassimilados quando alguns nutrientes limitam o crescimento das plantas, principalmente $\mathrm{P}$ e $\mathrm{N}$, o que pode ser uma estratégia de adaptação desenvolvida para aumentar a eficiência de absorção quando há limitação de P (FöHSE et al., 1988; Horst et al., 1993).

Destacaram-se as variedades Nitrodente e Antigo Maya que apresentaram os valores extremos -inferior e superior respectivamente - para essa relação. Isso sugere que a variedade Nitrodente, com a menor relação raiz/parte aérea, é a mais eficiente ao $\mathrm{P}$, pois mostrou melhor desenvolvimento da parte aérea nas três concentrações de P na solução, e sua produção de raízes a situou entre as melhores variedades. $\mathrm{Na}$ média, as variedades melhoradas, principalmente devido ao comportamento da Nitrodente, apresentaram valores da relação raiz/parte aérea significativamente menores que as locais. Sendo o aumento na relação raiz/parte aérea um sinal de sensibilidade à deficiência de $\mathrm{P}$ das plantas, deduz-se que as variedades locais foram mais sensíveis às concentrações de $P$ na solução nutritiva para as condições desse experimento. Entre as variedades locais, a Carioca apresentou a menor relação raiz/parte aérea, e Antigo Maya e Pedra Dourada, as maiores. Entre as melhoradas, Sol da Manhã, BR 105, BR 106 e BR 107 apresentaram relações raiz/parte aérea maiores que Nitrodente (Quadro 1). Algumas dessas variedades avaliadas em solo, por MACHADO (1995), mostraram valores da relação raiz/parte aérea semelhantes aos do experimento em solução nutritiva.

$\mathrm{O}$ conteúdo de $\mathrm{P}$ na parte aérea e raízes diferiu para variedades e doses (Quadro 2). O aumento de $\mathrm{P}$ na solução promoveu acréscimos no $\mathrm{P}$ acumulado em todas as partes das plantas. Entre as variedades, destacou-se a Nitrodente pelo maior conteúdo de $\mathrm{P}$ na parte aérea. Para as raízes, destacou-se a variedade 
Quadro 1. Produção de matéria seca da parte aérea e raízes e relação raiz/ parte aérea de matéria seca de variedades de milho cultivadas em solução nutritiva com três concentrações de P. Vasos com três plantas. Médias de cinco repetições

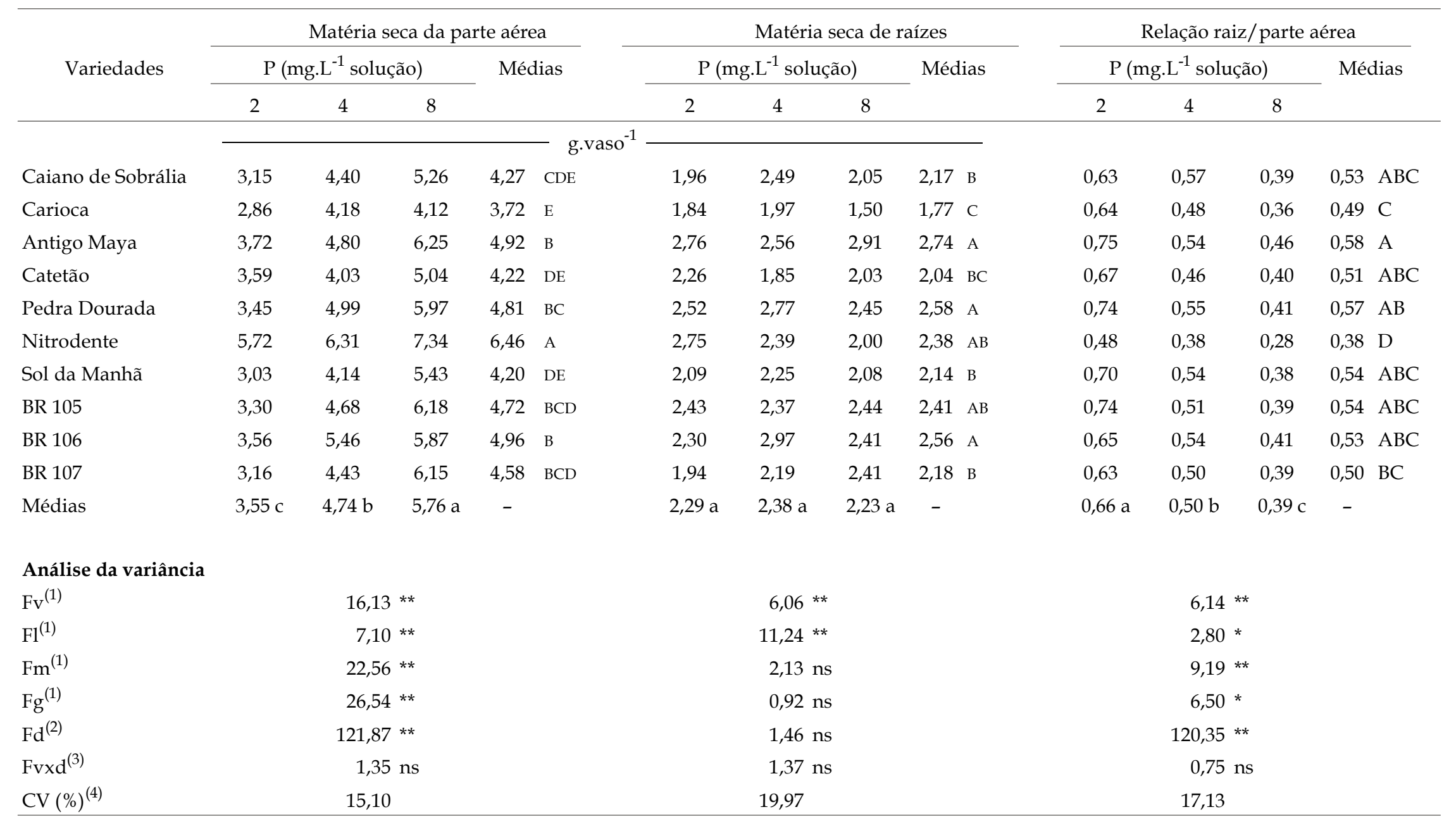

Médias seguidas pela mesma letra, minúscula na linha e maiúscula na coluna, dentro de cada variável, não diferem, entre si, ao nível de $5 \%$, pelo teste de Duncan. $\left({ }^{1}\right)$ Valor de $\mathrm{F}$ para variedades $(\mathrm{Fv})$, variedades locais $(\mathrm{Fl})$, variedades melhoradas $(\mathrm{Fm})$ e grupos $(\mathrm{Fg}) .\left({ }^{2}\right)$ Valor de $\mathrm{F}$ para as doses de $\mathrm{P}(\mathrm{Fd}) .\left({ }^{3}\right)$ Valor de $\mathrm{F}$ para a interação entre os tratamentos (Fvxd). $\left({ }^{4}\right)$ Coeficiente de variação. *, **: Significativo a 5\% e 1\%, respectivamente, pelo teste F. ns: Não significativo. 
local Antigo Maya. As variedades melhoradas acumularam, em média, maiores quantidades de $\mathrm{P}$ na parte aérea, com destaque para a Nitrodente. Já para o conteúdo de $\mathrm{P}$ das raízes, os grupos de variedades locais e melhoradas não se diferenciaram, porém, em cada grupo, destacaram-se Antigo Maya e Nitrodente respectivamente (Quadro 2).

As plantas extraíram praticamente todo o $\mathrm{P}$ colocado na solução, o que também foi observado por FURLANI et al. (1985) em milho cultivado em condições semelhantes na solução nutritiva. É importante considerar que as sementes não foram removidas quando se transferiram as plântulas do papel de germinação para os vasos com solução nutritiva. Alguns pesquisadores removem o endosperma em estudos dessa natureza.

Alves et al. (1988) atribuíram as diferenças na produção de matéria seca de híbridos de milho ao conteúdo de $\mathrm{P}$ das sementes, mas constataram também que a prática de remoção das sementes remanescentes após a germinação completa das plântulas, para minimizar a influência das sementes em ensaios de curta duração, não reduziu o efeito.

Neste experimento, as plantas se valeram do $\mathrm{P}$ originário das sementes no período inicial do desenvolvimento; isso explica os conteúdos de P acumulados na planta por vezes superiores aos fornecidos na solução nutritiva. Ao final do experimento, porém, observou-se a quase completa exaustão do P da solução; houve respostas diferenciadas na acumulação do nutriente pelas plantas entre as doses aplicadas, demonstrando a exigência do suprimento externo e a importância relativa do $\mathrm{P}$ das sementes nas determinações feitas por ocasião da colheita. Por essa razão, uma avaliação adequada das plantas em solução nutritiva para eficiência na absorção e uso de $\mathrm{P}$ requer plantas com 20-30 dias de idade; nesse período, a velocidade de absorção de $\mathrm{P}$ pelas raízes é máxima (CLARK, 1975), permitindo melhor distinção entre genótipos para essa característica. Além disso, nessa fase é possível observar diferenças significativas na translocação de $\mathrm{P}$ e no tamanho do sistema radicular e parte aérea das plântulas.

Quanto à partição do $\mathrm{P}$ absorvido, Nitrodente foi a variedade que transportou mais $\mathrm{P}$ para a parte aérea. As plantas alocaram, proporcionalmente, mais $\mathrm{P}$ nas raízes e menos na parte aérea na menor dose do nutriente na solução (Quadro 2). À medida que a concentração de $\mathrm{P}$ no meio aumentou, a proporção de $\mathrm{P}$ acumulada na parte aérea também se elevou, fato também observado por GILl et al. (1992) e Alves et al. (1998) em plantas de milho. SCHJORRING e JENSÉN (1987), entre outros, demonstraram que plantas defi- cientes retêm mais $\mathrm{P}$ nas raízes que plantas bem supridas.

Entre os grupos, as variedades melhoradas apresentaram maiores valores para a relação parte aérea/raízes de conteúdo de P. Dentre as locais, Catetão foi a variedade que proporcionalmente transferiu mais $\mathrm{P}$ para a parte aérea em detrimento das raízes. Nitrodente foi a variedade que apresentou maior capacidade de absorver e transportar uma apreciável quantidade do nutriente para as folhas sob condições de baixo P, aumentando a produção de matéria seca. MARSCHNER (1995) explicou que plantas deficientes aumentam a redistribuição de $\mathrm{P}$ da parte aérea para as raízes com conseqüente aumento na relação raiz/parte aérea de conteúdo de P. Segundo esse autor, sob condições de deficiência de P, ocorre maior retenção de $\mathrm{P}$ nas raízes e também uma redistribuição via floema, trazendo $P$ adicional às mesmas. Essa fração ciclada não só pode influenciar, mas também alterar a força do dreno dos fotossintetizados para as raízes às expensas da parte aérea.

Para a eficiência de utilização de $\mathrm{P}$, avaliada pelo índice (IE) proposto por SIDDIQI e GLASs (1981), que mede a produção de matéria seca em relação à concentração do nutriente nos tecidos, observaram-se diferenças entre as variedades testadas e entre as concentrações de P na solução (Quadro 3).

De modo geral, à medida que aumentou a concentração de P na solução e nas plantas, diminuiu o índice de eficiência de utilização de $P$ para a produção de matéria seca. Os maiores índices foram obtidos em 2 e $4 \mathrm{mg} . \mathrm{L}^{-1}$ de $\mathrm{P}$ na solução. A menor eficiência de utilização no nível mais alto de P na solução resultou do acúmulo de quantidade crescente de $\mathrm{P}$ proporcionalmente superior à matéria seca das plantas. Aumentando-se a dose de $\mathrm{P}$ de 2 para $4 \mathrm{mg}$. $\mathrm{L}^{-1}$ de solução, o incremento na produção de matéria seca total foi da ordem de $18 \%$ e no conteúdo total de $\mathrm{P}$, de 37\%. Do nível intermediário de P na solução ( 4 mg. $\left.\mathrm{L}^{-1}\right)$ para o maior ( $\left.8 \mathrm{mg} . \mathrm{L}^{-1}\right)$, o aumento na matéria seca foi de $11 \%$ apenas e na acumulação de P, 42\% (Quadros 1 e 2).

Furlani et al. (1985); Gill et al. (1992) e CiARELli et al. (1998) também observaram para milho redução na eficiência de utilização com o aumento na dose de $\mathrm{P}$ na solução. Dentre as variedades avaliadas, Nitrodente mostrou-se mais eficiente na utilização de $P$ para a produção de matéria seca, até mesmo na menor dose, seguida das variedades Pedra Dourada, Antigo Maya e BR 106. As menos eficientes foram Carioca, Catetão e Sol da Manhã. Na comparação entre grupos, verificou-se que as melhoradas foram, em média, mais eficientes que as locais, com diferenças significativas dentro dos grupos (Quadro 3). 
Quadro 2. Conteúdo de P da parte aérea e raízes e relação parte aérea/ raízes de conteúdo de P de variedades de milho cultivadas em solução nutritiva com três concentrações de P. Vasos com três plantas. Média de cinco repetições

\begin{tabular}{|c|c|c|c|c|c|c|c|c|c|c|c|c|c|c|c|}
\hline \multirow{3}{*}{ Variedades } & \multicolumn{5}{|c|}{ Conteúdo de $\mathrm{P}$ da parte aérea } & \multicolumn{5}{|c|}{ Conteúdo de $\mathrm{P}$ das de raízes } & \multicolumn{5}{|c|}{ Relação parte aérea/raiz } \\
\hline & \multicolumn{3}{|c|}{ P (mg.L ${ }^{-1}$ solução) } & \multirow{2}{*}{\multicolumn{2}{|c|}{ Médias }} & \multicolumn{3}{|c|}{ P (mg.L -1 $^{-1}$ solução) } & \multirow{2}{*}{\multicolumn{2}{|c|}{ Médias }} & \multicolumn{3}{|c|}{ P (mg.L ${ }^{-1}$ solução) } & \multirow{2}{*}{\multicolumn{2}{|c|}{ Médias }} \\
\hline & 2 & 4 & 8 & & & 2 & 4 & 8 & & & 2 & 4 & 8 & & \\
\hline & & 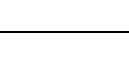 & & & & ig.vaso ${ }^{-}$ & & & & & & & & & \\
\hline Caiano de Sobrália & 4,68 & 9,42 & 19,40 & 11,17 & $\mathrm{BC}$ & 3,00 & 4,68 & 5,42 & 4,37 & $\mathrm{BC}$ & 1,57 & 2,03 & 3,61 & 2,40 & $\mathrm{BC}$ \\
\hline Carioca & 4,51 & 9,90 & 18,16 & 10,82 & $\mathrm{BC}$ & 3,28 & 4,14 & 5,30 & 4,24 & $\mathrm{BC}$ & 1,38 & 2,36 & 3,46 & 2,40 & $\mathrm{BC}$ \\
\hline Antigo Maya & 5,26 & 9,99 & 18,91 & 11,39 & $\mathrm{BC}$ & 4,23 & 4,56 & 6,25 & 5,01 & A & 1,28 & 2,19 & 3,03 & 2,17 & $\mathrm{C}$ \\
\hline Catetão & 6,92 & 9,74 & 17,07 & 11,25 & $\mathrm{BC}$ & 3,51 & 3,37 & 4,82 & 3,90 & C & 1,87 & 2,98 & 3,63 & 2,83 & B \\
\hline Pedra Dourada & 4,60 & 9,40 & 17,06 & 10,36 & $\mathrm{C}$ & 3,22 & 3,33 & 5,30 & 4,28 & $\mathrm{BC}$ & 1,47 & 2,21 & 3,27 & 2,32 & $\mathrm{C}$ \\
\hline Nitrodente & 8,72 & 13,49 & 22,72 & 14,98 & A & 3,91 & 4,35 & 5,07 & 4,44 & B & 2,26 & 3,13 & 4,63 & 3,34 & $\mathrm{~A}$ \\
\hline Sol da Manhã & 4,91 & 8,59 & 19,58 & 11,03 & $\mathrm{BC}$ & 3,17 & 4,01 & 5,05 & 4,08 & $\mathrm{BC}$ & 1,55 & 2,18 & 3,91 & 2,55 & $\mathrm{BC}$ \\
\hline BR 105 & 4,62 & 9,08 & 20,51 & 11,40 & $\mathrm{BC}$ & 3,78 & 4,29 & 5,40 & 4,49 & В & 1,22 & 2,15 & 4,02 & 2,46 & $\mathrm{BC}$ \\
\hline BR 106 & 5,45 & 10,62 & 19,05 & 11,71 & B & 3,53 & 4,32 & 5,11 & 4,32 & $\mathrm{BC}$ & 1,55 & 2,50 & 3,83 & 2,63 & $\mathrm{BC}$ \\
\hline BR 107 & 5,21 & 9,60 & 18,44 & 11,08 & $\mathrm{BC}$ & 2,87 & 3,89 & 4,99 & 3,92 & $\mathrm{C}$ & 1,88 & 2,54 & 3,96 & 2,79 & B \\
\hline Médias & $5,49 \mathrm{c}$ & $9,97 \mathrm{~b}$ & $19,09 \mathrm{a}$ & - & & $3,45 \mathrm{c}$ & $4,19 \mathrm{~b}$ & $5,27 \mathrm{a}$ & - & & $1,60 \mathrm{c}$ & $2,43 \mathrm{~b}$ & 3,73 a & - & \\
\hline \multicolumn{16}{|l|}{ Análise da variância } \\
\hline $\mathrm{Fv}^{(1)}$ & \multicolumn{5}{|c|}{$9,61 * *$} & \multicolumn{5}{|c|}{$4,08 * *$} & \multicolumn{5}{|c|}{$5,48 * *$} \\
\hline $\mathrm{Fl}^{(1)}$ & \multicolumn{5}{|c|}{$1,02 \mathrm{~ns}$} & \multicolumn{5}{|c|}{$6,52 * *$} & \multicolumn{5}{|c|}{$2,95 *$} \\
\hline $\mathrm{Fm}^{(1)}$ & \multicolumn{5}{|c|}{$16,53 * *$} & \multicolumn{5}{|c|}{$2,35 *$} & \multicolumn{5}{|c|}{$6,00 * *$} \\
\hline $\mathrm{Fg}^{(1)}$ & \multicolumn{5}{|c|}{$16,28 * *$} & \multicolumn{5}{|c|}{$1,24 \mathrm{~ns}$} & \multicolumn{5}{|c|}{$13,53 * *$} \\
\hline $\mathrm{Fd}^{(2)}$ & \multicolumn{5}{|c|}{955,06 ** } & \multicolumn{5}{|c|}{$110,46 * *$} & \multicolumn{5}{|c|}{$189,78 * *$} \\
\hline $\mathrm{Fvxd}^{(3)}$ & \multicolumn{5}{|c|}{$1,54 \mathrm{~ns}$} & \multicolumn{5}{|c|}{$1,10 \mathrm{~ns}$} & \multicolumn{5}{|c|}{$0,82 \mathrm{~ns}$} \\
\hline $\mathrm{CV}(\%)^{(4)}$ & \multicolumn{3}{|c|}{13,77} & & & & 14,3 & & & & & 21,3 & & & \\
\hline
\end{tabular}

Médias seguidas pela mesma letra, minúscula na linha e maiúscula na coluna, dentro de cada variável, não diferem, entre si, ao nível de $5 \%$ pelo teste de Duncan. $\left({ }^{1}\right)$ Valor de $\mathrm{F}$ para variedades $(\mathrm{Fv})$, variedades locais $(\mathrm{Fl})$, variedades melhoradas $(\mathrm{Fm})$ e grupos $(\mathrm{Fg}) .\left({ }^{2}\right)$ Valor de $\mathrm{F}$ para as doses de $\mathrm{P}(\mathrm{Fd}) .\left({ }^{3}\right)$ Valor de $\mathrm{F}$ para a interação entre os tratamentos (Fvxd). $\left({ }^{4}\right)$ Coeficiente de variação. *, **: Significativo a 5\% e 1\%, respectivamente, pelo teste F. ns: Não significativo. 
Quadro 3. Índices de eficiência de utilização (IE) de fósforo das variedades de milho cultivadas em solução nutritiva com três concentrações de P. Vasos com três plantas. Médias de cinco repetições

\begin{tabular}{|c|c|c|c|c|}
\hline \multirow{3}{*}{ Variedades } & \multicolumn{4}{|c|}{ Eficiência de utilização de P } \\
\hline & \multicolumn{3}{|c|}{ P (mg.L ${ }^{-1}$ na solução) } & \multirow[t]{2}{*}{ Médias } \\
\hline & 2 & 4 & 8 & \\
\hline & \multicolumn{4}{|c|}{$-\mathrm{g}^{2} \cdot \mathrm{mg} \mathrm{P}^{-1}$} \\
\hline Caiano de Sobrália & 3,43 & 3,39 & 2,17 & $3,00 \mathrm{DEF}$ \\
\hline Carioca & 2,90 & 2,77 & 1,35 & $2,34 \mathrm{~F}$ \\
\hline Antigo Maya & 4,46 & 3,77 & 3,41 & $3,88 \mathrm{ABC}$ \\
\hline Catetão & 3,39 & 2,66 & 2,30 & $2,78 \mathrm{EF}$ \\
\hline Pedra Dourada & 4,60 & 4,52 & 3,21 & $4,11 \mathrm{AB}$ \\
\hline Nitrodente & 5,82 & 4,32 & 3,17 & $4,44 \mathrm{~A}$ \\
\hline Sol da Manhã & 3,25 & 3,31 & 2,33 & $2,96 \mathrm{DEF}$ \\
\hline BR 105 & 3,97 & 3,87 & 2,94 & $3,59 \mathrm{BCD}$ \\
\hline BR 106 & 3,87 & 4,84 & 2,85 & $3,85 \mathrm{ABC}$ \\
\hline BR 107 & 3,29 & 3,28 & 3,20 & $3,25 \mathrm{CDE}$ \\
\hline Médias & $3,90 \mathrm{a}$ & $3,67 \mathrm{a}$ & $2,69 \mathrm{~b}$ & - \\
\hline Análise de variância & \multicolumn{4}{|c|}{ IE } \\
\hline $\mathrm{Fv}^{(1)}$ & \multicolumn{4}{|c|}{$8,61^{* *}$} \\
\hline $\mathrm{Fl}^{(1)}$ & \multicolumn{4}{|c|}{$11,07^{* *}$} \\
\hline $\mathrm{Fm}^{(1)}$ & \multicolumn{4}{|c|}{$6,34^{* *}$} \\
\hline $\mathrm{Fg}^{(1)}$ & \multicolumn{4}{|c|}{$7,84^{* *}$} \\
\hline $\mathrm{Fd}^{(2)}$ & \multicolumn{4}{|c|}{$27,07^{* *}$} \\
\hline $\mathrm{Fvxd}^{(3)}$ & \multicolumn{4}{|c|}{$1,27 \mathrm{~ns}$} \\
\hline CV $(\%)^{(4)}$ & \multicolumn{4}{|c|}{25,48} \\
\hline
\end{tabular}

Médias seguidas pela mesma letra, minúscula na linha e maiúscula na coluna, não diferem, entre si, ao nível de $5 \%$ pelo teste de Duncan. $\left({ }^{1}\right)$ Valor de F para as variedades $(\mathrm{Fv})$, variedades locais $(\mathrm{Fl})$, variedades melhoradas $(\mathrm{Fm})$ e grupos $(\mathrm{Fg}) .\left({ }^{2}\right)$ Valor de $\mathrm{F}$ para as doses de $\mathrm{P}(\mathrm{Fd}) .\left({ }^{3}\right)$ Valor de $\mathrm{F}$ para a interação entre os tratamentos (Fvxd). $\left({ }^{4}\right)$ Coeficiente de variação. ${ }^{*}, * *$ : Significativo a $5 \%$ e $1 \%$, respectivamente, pelo teste F. ns: Não significativo.

A superioridade de Nitrodente para a eficiência de utilização de $\mathrm{P}$ reflete seu desempenho nas demais variáveis analisadas: foi a variedade que mais produziu matéria seca de parte aérea e uma das que mais produziram raízes; alocou preferencialmente a matéria seca produzida na parte aérea, bem como o $\mathrm{P}$ absorvido. Pedra Dourada, Antigo Maya e BR 106 destacaram-se quanto às características relacionadas ao sistema radicular, apresentando os maiores valores de matéria seca, da razão raiz/parte aérea e conteúdo de $\mathrm{P}$ nas raízes. Caiano, Catetão e Carioca, menos eficientes na utilização de $\mathrm{P}$, produziram menos matéria seca de parte aérea e estiveram entre os materiais de maior razão raiz/parte aérea (Quadros 1 e 2). Tal variabilidade genotípica em milho para a eficiência ao $\mathrm{P}$ tem sido relatada com freqüência na literatura (FurLANI et al., 1985; Alves et al., 1988; FAGERIA e BALIGAR, 1997; MACHADO et al., 1999).

Estudando as correlações entre o índice de eficiência e as outras variáveis, verificou-se que a produção de matéria seca total e o teor de $\mathrm{P}$ das raízes foram os principais determinantes da eficiência de utilização de $P$ das variedades nas condições deste experimento.

Todas as variedades apresentaram correlações positivas expressivas entre a produção de matéria seca total e a eficiência de utilização de $\mathrm{P}$ em pelo menos um dos níveis do nutriente na solução, e os coeficientes de correlação $(r)$ variaram de $0,86^{*}$ a $1,00^{* *}$. Com exceção da variedade local Antigo Maya, as demais variedades apresentaram correlações negativas significativas entre o teor de $\mathrm{P}$ das raízes e a eficiência de utilização em pelo menos dois níveis de $P$ na solução nutritiva. Os coeficientes ( $r$ ) variaram de $-0,85^{*}$ a $-0,99^{* *}$. Isso indica que a combinação entre elevada produção de matéria seca e baixa concentração de $P$ nas raízes e vice-versa resultou em maior ou menor eficiência de utilização de $\mathrm{P}$ das variedades.

\subsection{Avaliação de variedades de milho para eficiência ao fósforo em campo}

Quanto à produção de matéria seca pelas partes da planta, observou-se que as variedades produziram quantidades semelhantes de palha. A variação foi maior para as produções de sabugos e grãos, pelas quais se diferenciaram os materiais. As variedades melhoradas foram, em média, mais produtivas que as locais; apresentaram maiores índices de colheita e menor produção de palha, indicando a prioridade dada ao rendimento de grãos em relação à produção de material vegetativo (Quadro 4).

As variedades melhoradas BR 106 e Nitrodente atingiram os maiores rendimentos de grãos. Entretanto, apenas as variedades locais Antigo Maya, Pedra Dourada e Catetão foram inferiores, sendo Caiano e Carioca as que alcançaram produção semelhante à das melhoradas Sol da Manhã, BR 105 e BR 107.

Na produção de sabugos, destacou-se a variedade local Catetão, bem rústica, com sabugos finos, compridos e de menor massa. A produção de sabugos das variedades locais foi significativamente menor que a das melhoradas (Quadro 4).

Nitrodente e BR 106 diferenciaram-se da variedade local Catetão, respectivamente, com os maiores e o menor índice de colheita (produção de grãos/biomassa total). $\mathrm{O}$ crescimento vegetativo vigoroso é característico da variedade local Catetão. 
Observou-se que as variedades melhoradas, apesar das pequenas diferenças para o índice de colheita, apresentaram valores médios superiores aos das variedades locais.

As condições de fertilidade do solo e de disponibilidade adequada de nutrientes e água no ambiente deste experimento maximizaram o potencial produtivo das variedades avaliadas, que alcançaram excelentes níveis de produtividade, com as variedades locais comparáveis às melhoradas. Verificou-se tal desempenho produtivo para as variedades locais em várias situações ambientais (MACHADO et al., 1998, 1999).

Quanto aos teores e conteúdos de P na palha, sabugos e grãos (Quadro 5) houve diferença apenas

Quadro 4. Produção de palha, sabugos e grãos e índice de colheita de variedades de milho. Médias de seis repetições

\begin{tabular}{|c|c|c|c|c|}
\hline Variedades & Palha & Sabugos & Grãos & $\begin{array}{c}\text { Indice de } \\
\text { colheita }\end{array}$ \\
\hline & & - kg.ha ${ }^{-1}$ & & \\
\hline \multicolumn{4}{|l|}{ Caiano de } & $0,60 \mathrm{ABC}$ \\
\hline Carioca & 3.867 & $1.204 \mathrm{AB}$ & $7.590 \mathrm{AB}$ & 0,60 АВС \\
\hline $\begin{array}{l}\text { Antigo } \\
\text { Maya }\end{array}$ & 3.746 & $1.214 \mathrm{AB}$ & $7.010 \mathrm{BC}$ & $0,58 \mathrm{ABC}$ \\
\hline Catetão & 3.719 & $919 \mathrm{C}$ & $5.983 C$ & $0,56 \mathrm{C}$ \\
\hline \multicolumn{5}{|l|}{ Pedra } \\
\hline Nitrodente & 3.437 & $1.387 \mathrm{~A}$ & $8.463 \mathrm{~A}$ & 0,64 A \\
\hline $\begin{array}{l}\text { Sol da } \\
\text { Manhã }\end{array}$ & 3.525 & $1.395 \mathrm{~A}$ & $7.807 \mathrm{AB}$ & $0,61 \mathrm{ABC}$ \\
\hline BR 105 & 3.214 & 1.107 B & $7.567 \mathrm{AB}$ & $0,63 \mathrm{AB}$ \\
\hline BR 106 & 3.575 & $1.292 \mathrm{AB}$ & $8.480 \mathrm{~A}$ & 0,64 A \\
\hline BR 107 & 3.145 & $1.276 \mathrm{AB}$ & $7.450 \mathrm{AB}$ & 0,63 в \\
\hline Médias & 3.593 & 1.245 & 7.502 & 0,61 \\
\hline \multicolumn{5}{|c|}{ Análise da variância } \\
\hline $\mathrm{FV}_{\mathrm{V}}^{(1)}$ & $1,51 \mathrm{~ns}$ & $5,73 * *$ & $3,15 * *$ & 2,92 * \\
\hline $\mathrm{Fl}^{(1)}$ & $0,28 \mathrm{~ns}$ & $7,69 * *$ & $2,53 *$ & $1,00 \mathrm{~ns}$ \\
\hline $\mathrm{Fm}^{(1)}$ & $0,75 \mathrm{~ns}$ & $3,74 *$ & $1,46 \mathrm{~ns}$ & $0,27 \mathrm{~ns}$ \\
\hline $\mathrm{Fg}^{(1)}$ & $9,44^{* *}$ & $5,88^{* *}$ & $12,39 * *$ & $14,27^{* *}$ \\
\hline CV (\%) ${ }^{(2)}$ & 15,01 & 11,87 & 13,25 & 6,91 \\
\hline
\end{tabular}

Médias seguidas pela mesma letra, minúscula na linha e maiúscula na coluna, não diferem, entre si, ao nível de $5 \%$ pelo teste de Duncan. $\left({ }^{1}\right)$ Valor de F para as variedades $(\mathrm{Fv})$, variedades locais $(\mathrm{Fl})$, variedades melhoradas $(\mathrm{Fm})$ e grupos $(\mathrm{Fg}) .\left(^{2}\right)$ Coeficiente de variação. ${ }^{*},{ }^{* *}$ : Significativo a $5 \%$ e $1 \%$, respectivamente, pelo teste F. ns: Não significativo. nos grãos; Catetão e Nitrodente apresentaram, respectivamente, a maior e a menor concentração do nutriente. Os sabugos apresentaram maiores concentrações de $\mathrm{P}$ em relação à palha, diferentemente do observado por CLARK (1975), também em milho, quando os sabugos tiveram a menor concentração dentre as partes da planta. De acordo, porém, com o que foi verificado por GoRsLine et al. (1965), quando a palha (colmo e folhas) apresentou concentração de P menor que a dos sabugos e dos grãos.

Neste experimento evidenciaram-se diferenças para o teor de P nos grãos entre e dentro dos grupos de variedades locais e melhoradas; as locais apresentaram, em média, teores superiores ao das melhoradas.

As variedades não se diferenciaram significativamente quanto ao $\mathrm{P}$ acumulado na palha, nos grãos e sabugos (Quadro 5). A quantidade de P acumulada nos grãos pelas variedades locais é semelhante à obtida para algumas delas em estudo anterior, quando cultivadas no mesmo solo e com o mesmo nível de $\mathrm{P}$ (MACHADO et al., 1999). Isso, mais uma vez, confirma o controle genético da acumulação de nutrientes e o efeito exercido pelas condições ambientais, sobretudo da fertilidade do solo na quantidade acumulada.

Concentrações e conteúdos de P nos grãos de milho de germoplasma tropical semelhantes foram verificados por FeIL et al. (1992), em cujo trabalho havia elevado teor de $\mathrm{P}$ disponível no solo e o nível de adubação nitrogenada foi o mesmo empregado neste ensaio. No estudo de FeIL et al. (1992), os sabugos também apresentaram o menor conteúdo de $\mathrm{Pe}$ e, pela literatura, tem-se que a remobilização a partir deles, bem como a do colmo e palha da espiga, precede à das folhas (GORSLINE, 1965; CLARK, 1975).

Os resultados do presente experimento evidenciaram, em função do conteúdo de $\mathrm{P}$ nas partes da planta, a intensa remobilização do $P$ das partes vegetativas para os grãos, que constituem os principais órgãos de armazenamento do $\mathrm{P}$ ao final do ciclo comportamento típico dos cereais (GoRsLINE et al., 1965; Clark, 1975; SChulthess et al., 1997).

As diferentes fases da ontogenia vegetal estão relacionadas às exigências ou demandas diferenciadas em P (BlaIR, 1993). O P absorvido após a polinização é necessário para a síntese de carboidratos que irão assegurar o potencial de rendimento das plantas, sendo ambos transportados para os grãos (JONES et al., 1992). Além do envolvimento no metabolismo do carbono, o P está ligado ao metabolismo dos lipídeos e das proteínas (MARSCHNER, 1995) que são armazenados nos grãos; a falta do nutriente provoca a formação de espigas defeituosas, tortas e com falhas nas fileiras de grãos, bem como o processo de maturação 
Quadro 5. Teor e conteúdo de P na palha, sabugos e grãos de variedades de milho. Médias de seis repetições

\begin{tabular}{|c|c|c|c|c|c|c|}
\hline \multirow{2}{*}{ Variedades } & \multicolumn{3}{|c|}{ Teores de $\mathrm{P}$} & \multicolumn{3}{|c|}{ Conteúdo de P } \\
\hline & Palha & Sabugos & Grãos $^{(1)}$ & Palha & Sabugos & Grãos \\
\hline & & g.kg-1 & & & kg.ha ${ }^{-1}$ & - \\
\hline Caiano de Sobrália & 0,24 & 0,43 & $4,13 \mathrm{CD}$ & 0,96 & 0,57 & 31,07 \\
\hline Carioca & 0,28 & 0,45 & 4,29 вCD & 1,04 & 0,55 & 32,52 \\
\hline Antigo Maya & 0,27 & 0,45 & $4,30 \mathrm{BCD}$ & 1,01 & 0,55 & 29,82 \\
\hline Catetão & 0,21 & 0,38 & $5,35 \mathrm{~A}$ & 0,80 & 0,34 & 31,96 \\
\hline Pedra Dourada & 0,21 & 0,40 & 4,38 вс & 0,86 & 0,55 & 31,27 \\
\hline Nitrodente & 0,22 & 0,49 & $3,70 \mathrm{D}$ & 0,75 & 0,68 & 31,35 \\
\hline Sol da Manhã NF & 0,23 & 0,42 & $4,86 \mathrm{AB}$ & 0,82 & 0,59 & 37,91 \\
\hline BR 105 & 0,23 & 0,41 & $3,98 \mathrm{CD}$ & 0,73 & 0,47 & 30,82 \\
\hline BR 106 & 0,19 & 0,36 & $3,92 \mathrm{CD}$ & 0,69 & 0,47 & 33,24 \\
\hline BR 107 & 0,24 & 0,39 & $4,47 \mathrm{BC}$ & 0,76 & 0,51 & 33,05 \\
\hline Médias & 0,23 & 0,42 & 4,34 & 0,84 & 0,53 & 32,30 \\
\hline \multicolumn{7}{|l|}{ Análise da variância } \\
\hline $\mathrm{Fv}^{(1)}$ & $0,54 \mathrm{~ns}$ & $0,66 \mathrm{~ns}$ & $6,63^{* *}$ & $0,61 \mathrm{~ns}$ & $1,77 \mathrm{~ns}$ & $1,01 \mathrm{~ns}$ \\
\hline $\mathrm{Fl}^{(1)}$ & $0,70 \mathrm{~ns}$ & $0,51 \mathrm{~ns}$ & $6,86^{* *}$ & $0,42 \mathrm{~ns}$ & $2,10 \mathrm{~ns}$ & $0,21 \mathrm{~ns}$ \\
\hline $\mathrm{Fm}^{(1)}$ & $0,30 \mathrm{~ns}$ & $0,92 \mathrm{~ns}$ & $6,39 * *$ & $0,09 \mathrm{~ns}$ & $1,82 \mathrm{~ns}$ & $1,58 \mathrm{~ns}$ \\
\hline $\mathrm{Fg}^{(1)}$ & $0,50 \mathrm{~ns}$ & $0,08 \mathrm{~ns}$ & $6,59 *$ & $3,42 \mathrm{~ns}$ & $0,36 \mathrm{~ns}$ & $1,92 \mathrm{~ns}$ \\
\hline $\mathrm{CV}(\%)^{(2)}$ & 37,38 & 26,98 & 10,53 & 45,94 & 31,97 & 16,88 \\
\hline
\end{tabular}

Médias seguidas pela mesma letra, nas colunas, não diferem entre si pelo teste de Duncan ao nível de $5 \%$. $\left({ }^{1}\right)$ Valor de F para as variedades de milho $(\mathrm{Fv})$, variedades locais $(\mathrm{Fl})$, variedades melhoradas $(\mathrm{Fm})$ e para os grupos $(\mathrm{Fg}) .\left(^{2}\right)$ Coeficiente de variação. *,**: Significativo a 5\% e 1\%, respectivamente, pelo teste F. ns: Não significativo.

é retardado e desuniforme. O fluxo de $\mathrm{P}$ entre as partes da planta depende da demanda dos órgãos que constituem os drenos e da capacidade de suprimento daqueles que representam as fontes. Mudanças nessa relação fonte/dreno, refletidas pelos conteúdos de $\mathrm{P}$ nas partes das plantas, podem relacionar-se com a eficiência de absorção e utilização de P. Neste experimento, as variedades avaliadas não apresentaram variação quanto ao conteúdo de $\mathrm{P}$ nas partes, não permitindo sua diferenciação pela força das fontes e dos drenos.

Os índices de eficiência das variedades de milho foram calculados com o objetivo de identificar a contribuição relativa dos vários processos de aquisição e distribuição do $P$ na variação total da eficiência do uso de P (Quadro 6). Esses índices foram descritos por Moll et al. (1982) para caracterizar a eficiência ao N. Entretanto, vêm sendo aplicados com bastante propriedade e sucesso na discriminação de eficiência ao P em cereais (JonEs et al., 1992; BLAIR, 1993).

$\mathrm{O}$ índice $\mathrm{Pg} / \mathrm{Ns}$ mede o uso eficiente do fertilizante fosfatado; as variedades que atingiram os maio- res valores para essa relação foram (em ordem decrescente): BR $106>$ Nitrodente > Sol da Manhã $>$ Carioca > BR $105>$ Caiano. Comportamento semelhante foi observado em relação ao índice de colheita. O índice Np/Ns mede a eficiência de absorção do nutriente; sob esse aspecto as variedades testadas não diferiram significativamente entre si, sugerindo que a absorção não foi o fator determinante para diferenciá-las quanto à maior ou menor eficiência ao P. A relação $\mathrm{Pg} / \mathrm{Np}$, também denominada razão de eficiência de $\mathrm{P}$ (JONES et al., 1992), mede a produção de grãos (Pg) por unidade do nutriente contido na planta $(\mathrm{Np})$; Nitrodente apresentou maior valor para esse índice, indicando um metabolismo mais eficiente na assimilação e conversão do nutriente absorvido, o que pode explicar, provavelmente, a maior produtividade alcançada por essa variedade, seguida da BR 105 e Caiano. Os menores valores para esse índice foram os de Sol da Manhã e Catetão. A variedade Nitrodente se mostrou a mais eficiente também quanto ao índice $\mathrm{Pg} / \mathrm{Ng}$, que relaciona os grãos produzidos $(\mathrm{Pg})$ por unidade do nutriente nos grãos $(\mathrm{Ng})$. Por último, o 
índice $\mathrm{Ng} / \mathrm{Np}$ ou índice de colheita de $\mathrm{P}$ (JonEs et al., 1992) descreve a fração total do nutriente na planta $(\mathrm{Np})$ que é transportada para o grão $(\mathrm{Ng})$. Não houve, para esse índice, diferença entre os materiais, que translocaram uniformemente quase todo o $\mathrm{P}$ absorvido para os grãos.

Verificaram-se contrastes estatísticos entre e dentro dos grupos de variedades locais e melhoradas para os índices $\mathrm{Pg} / \mathrm{Ns}$ (entre locais e melhoradas), $\mathrm{Pg} / \mathrm{Np}$ e $\mathrm{Pg} / \mathrm{Ng}$ (entre e dentro dos grupos de locais e melhoradas). As variedades melhoradas foram significativamente mais eficientes no uso $(\mathrm{Pg} / \mathrm{Ns})$ e na utilização (pelos dois índices) que as locais. Dentro dos grupos, para a razão de eficiência $\mathrm{Pg} / \mathrm{Np}$, Caiano foi a variedade superior entre as locais, enquanto Nitrodente, seguida de BR 105 e BR 106, as superiores entre as melhoradas. Para o índice $\mathrm{Pg} / \mathrm{Ng}$, Carioca e Caiano se destacaram entre as variedades locais e, da mesma forma que para o índice anterior, Nitrodente, BR 105 e BR 106 foram as superiores entre as melhoradas.
Estudando as correlações entre os índices de eficiência e as demais variáveis obtidas para as variedades, verificou-se que a produção de grãos, o índice de colheita, o teor e o conteúdo de $\mathrm{P}$ dos grãos foram as variáveis determinantes dos índices de eficiência ao P para as condições de disponibilidade do nutriente deste experimento. A produção de grãos, obviamente, apresentou correlação positiva e altamente significativa (a $1 \%$ pelo teste $\mathrm{T}$ de Student) com a eficiência de uso do fertilizante fosfatado (índice $\mathrm{Pg} / \mathrm{Ns}$ ), sendo para todas as variedades o coeficiente de correlação (r) entre estes parâmetros igual a 1,00** . Correlações altamente significativas entre produção e eficiência de absorção (índice $\mathrm{Np} / \mathrm{Ns}$ ) foram observadas para Caiano $\left(r=0,97^{* *}\right)$, Antigo Maya $\left(r=0,98^{* *}\right)$ e BR $105\left(\mathrm{r}=0,95^{* *}\right)$. O índice de colheita também se relacionou de forma positiva com a eficiência de uso (Pg/Ns) nas variedades Caiano $\left(\mathrm{r}=0,83^{*}\right)$, BR 105 $\left(\mathrm{r}=0,81^{*}\right)$, Nitrodente $\left(\mathrm{r}=0,87^{*}\right)$, Carioca $\left(\mathrm{r}=0,95^{* *}\right)$, Antigo Maya $\left(r=0,99^{* *}\right)$ e Catetão $\left(r=0,91^{* *}\right)$. Todas as variedades apresentaram correlação inversa alta-

Quadro 6. Índices de eficiência ao P de variedades de milho. Médias de seis repetições

\begin{tabular}{|c|c|c|c|c|c|}
\hline & $\mathrm{Pg} / \mathrm{Ns}^{(1)}$ & $\mathrm{Np} / \mathrm{Ns}^{(1)}$ & $\mathrm{Pg} / \mathrm{Np}^{(1)}$ & $\mathrm{Pg} / \mathrm{Ng}^{(1)}$ & $\mathrm{Ng} / \mathrm{Np}^{(1)}$ \\
\hline Variedades & $\begin{array}{c}\text { (kg grãos/ } \\
\text { kg P aplicado) }\end{array}$ & $\begin{array}{l}\text { (kg P planta/ } \\
\text { kg P aplicado) }\end{array}$ & $\begin{array}{l}\text { (kg grãos/ } \\
\text { kg P planta) }\end{array}$ & $\begin{array}{l}\text { (kg grãos / } \\
\text { kg P grãos) }\end{array}$ & $\begin{array}{l}\text { (kg P grãos } \\
\text { kg P planta) }\end{array}$ \\
\hline Caiano de Sobrália & $171,06 A B$ & 0,74 & 231,30 АВС & 243,07 АВC & 0,96 \\
\hline Carioca & $172,50 \mathrm{AB}$ & 0,78 & 224,99 вС & $236,23 \mathrm{ABC}$ & 0,95 \\
\hline Antigo Maya & 159,32 вС & 0,71 & 221,73 вС & 233,59 вС & 0,96 \\
\hline Catetão & $135,99 \mathrm{C}$ & 0,75 & $181,33 \mathrm{D}$ & $187,93 \mathrm{D}$ & 0,97 \\
\hline Pedra Dourada & 162,27 BC & 0,74 & 220,58 вс & 230,43 вС & 0,96 \\
\hline Nitrodente & 192,35 A & 0,75 & 260,99 A & 272,95 A & 0,96 \\
\hline Sol da Manhã & $177,42 \mathrm{AB}$ & 0,89 & $199,34 \mathrm{CD}$ & $206,89 \mathrm{CD}$ & 0,96 \\
\hline BR 105 & $171,97 \mathrm{AB}$ & 0,73 & $249,53 \mathrm{AB}$ & 260,78 АВ & 0,96 \\
\hline BR 106 & 192,73 A & 0,78 & $247,32 \mathrm{AB}$ & 255,92 АВ & 0,97 \\
\hline BR 107 & $169,32 \mathrm{AB}$ & 0,78 & 217,72 вС & 226,18 вС & 0,96 \\
\hline \multicolumn{6}{|l|}{ Análise da variância } \\
\hline $\mathrm{Fv}^{(2)}$ & $3,15 * *$ & $0,99 \mathrm{~ns}$ & $4,84^{* *}$ & $4,59 * *$ & $1,05 \mathrm{~ns}$ \\
\hline $\mathrm{Fl}^{(2)}$ & $2,53 \mathrm{~ns}$ & $0,21 \mathrm{~ns}$ & $3,37 *$ & $3,48 *$ & $0,63 \mathrm{~ns}$ \\
\hline $\mathrm{Fm}^{(2)}$ & $1,46 \mathrm{~ns}$ & $1,67 \mathrm{~ns}$ & $5,59 * *$ & $5,34 * *$ & $0,63 \mathrm{~ns}$ \\
\hline $\mathrm{Fg}^{(2)}$ & $12,39 * *$ & $1,67 \mathrm{~ns}$ & $7,73^{* *}$ & $6,05 *$ & $0,001 \mathrm{~ns}$ \\
\hline $\mathrm{CV}(\%)^{(3)}$ & 13,25 & 16,20 & 11,73 & 12,24 & 1,51 \\
\hline
\end{tabular}

Médias seguidas pela mesma letra nas colunas não diferem, entre si, ao nível de $5 \%$, pelo teste de Duncan. $\left({ }^{1}\right) \mathrm{Pg} / \mathrm{Ns}$ : avalia o uso eficiente do fertilizante aplicado para produção de grãos; $\mathrm{Np} / \mathrm{Ns}$ : avalia a eficiência de absorção do nutriente pela planta; $\mathrm{Pg} / \mathrm{Np}$ : avalia a eficiência de utilização do nutriente para a produção de grãos; $\mathrm{Pg} / \mathrm{Ng}$ : avalia a produção de grãos por unidade do nutriente nos grãos; $\mathrm{Ng} / \mathrm{Np}$ : avalia a fração do total do nutriente na planta que é translocado para os grãos. $\left({ }^{2}\right)$ Valor de F para as variedades de milho $(\mathrm{Fv})$, variedades locais $(\mathrm{Fl})$, variedades melhoradas $(\mathrm{Fm})$ e para os grupos $(\mathrm{Fg}) .\left({ }^{3}\right)$ Coeficiente de variação. * ${ }^{* *}$ : Significativo a $5 \%$ e $1 \%$, respectivamente, pelo teste F. ns: Não significativo. 
mente significativa entre o teor de $\mathrm{P}$ nos grãos e os índices de eficiência de utilização de $\mathrm{P}(\mathrm{Pg} / \mathrm{Np}$ e $\mathrm{Pg} / \mathrm{Ng}$ ), apresentando valores de $\mathrm{r}$ variando entre $-0,91^{* *}$ e $-1,00^{* *}$. Também em todas as variedades se observou correlação altamente significativa, porém positiva, entre o conteúdo de $\mathrm{P}$ dos grãos e o índice de eficiência de absorção $\mathrm{Np} / \mathrm{Ns}\left(\mathrm{r}=0,99^{* *}\right.$ para Caiano e $1,00^{* *}$ para as demais). Em Pedra Dourada, Nitrodente, BR 105 e BR 106 o conteúdo de P dos grãos se relacionou inversamente, porém de forma significativa, com os índices de eficiência de utilização $\mathrm{Pg} / \mathrm{Np}$ e $\mathrm{Pg} / \mathrm{Ng}$. Os valores de $\mathrm{r}$ variaram de $-0,85^{*}$ a $-0,98^{* *}$. A correlação entre conteúdo de $\mathrm{P}$ dos grãos e $\mathrm{Pg} / \mathrm{Ns}$ (eficiência de uso do fertilizante aplicado) foi positiva e altamente significativa para Caiano $\left(\mathrm{r}=0,96^{* *}\right)$, Antigo Maya $\left(\mathrm{r}=0,98^{* *}\right)$ e BR 105 $\left(\mathrm{r}=0,95^{* *}\right)$.

Os índices forneceram medidas estáticas da eficiência ao $\mathrm{P}$, por não terem sido utilizados níveis diferenciados de fertilização fosfatada, ou realizadas amostragens em diversos estádios de desenvolvimento da planta, dada a importância da demanda pelo nutriente em função do estádio ontogenético. Apesar disso, sugeriram que a capacidade de obter o $\mathrm{P}$ do solo ou de translocá-lo para os grãos pode não ter determinado a eficiência de uso do $\mathrm{P}$ nessas variedades, e sim os mecanismos mais eficientes de utilização de $\mathrm{P}$ para a produção de grãos. Esses índices foram úteis também na caracterização das variedades, sobretudo os índices $\mathrm{Pg} / \mathrm{Np}$ e $\mathrm{Pg} / \mathrm{Ng}$, que sugeriram que o fator determinante das diferenças encontradas está relacionado com suas atividades metabólicas.

Deve-se considerar, entretanto, que a avaliação das variedades em experimento de campo, no qual se aplicou a dose recomendada, reduz a possibilidade de encontrar diferenças decorrentes de outros fatores que não os de utilização do $P$, já que a aquisição não foi limitada pela disponibilidade do nutriente. No experimento em solução nutritiva em que as doses de P eram mais limitantes, embora a produção de massa tenha sido o principal determinante da eficiência de utilização de $\mathrm{P}$, observaram-se variações consideráveis na absorção e transporte do $P$ para a parte aérea pelas variedades (Quadro 2). Isso foi, particularmente, evidente na concentração de $2 \mathrm{mg}$. $\mathrm{L}^{-1} \mathrm{de} \mathrm{P}$, em que as plantas apresentaram sintomas visuais de deficiência de P, como a coloração arroxeada e senescência de folhas inferiores. É conhecido na literatura que as variações na absorção e transporte de $\mathrm{P}$ são menos marcantes quando o P está em níveis mais abundantes (Loughman et al. 1983).

Concentrações de P muito baixas ou muito altas em solução nutritiva podem inibir o crescimento radi- cular de milho e de sorgo. Algumas espécies vegetais toleram mais P na solução nutritiva que outras; experiências com milho e sorgo indicam que a maior parte das soluções nutritivas contém quantidades de $\mathrm{P}$ excessivas, incluindo aqui a solução de Hoagland (31 mg.L $\mathrm{L}^{-1}$ de P) Clark (1982). Para estudos de eficiência ao $\mathrm{P}$ em milho, em condições de estresse, alguns autores têm utilizado concentrações da ordem de 5 a $100 \mu \mathrm{mol} . L^{-1}$ (GIll et al., 1992; Alves et al., 1998). Devese considerar, contudo, o sistema em que o experimento é realizado, o tamanho do recipiente, o volume de solução disponível para cada planta (número de plantas por recipiente) e o material genético com o qual está trabalhando (variedades, híbridos ou linhagens), que podem ter diferentes demandas ou exigências nutricionais.

FURLANI e FURLANI (1988) ao definirem a técnica para seleção de plantas de arroz, milho ou sorgo em solução nutritiva, em experimentos de curta duração (20 a 30 dias), sugeriram que nessa situação, para se obter o estresse de $\mathrm{P}$, a concentração na solução nutritiva deveria estar entre 2 e 4 mg. $\mathrm{L}^{-1}$ de P (ou 64 a $130 \mu \mathrm{mol} . \mathrm{L}^{-1}$ ) para recipientes de $3 \mathrm{~L}$ e sem renovação da solução, a fim de detectar diferenças entre os genótipos quanto à eficiência na absorção e utilização de $P$. Esses autores têm utilizado concentrações de $P$ próximas a esses limites para a avaliação e diferenciação de genótipos de milho, arroz e sorgo em estudos de eficiência de absorção e utilização do nutriente e de herança de caracteres relacionados à eficiência ao P (FURLANI et al., 1985, 1987, 1998; CIARELLI et al., 1998).

As variedades que acumularam maior massa na parte aérea em solução nutritiva (Quadro 1), Nitrodente e BR 106, foram as mesmas que em campo atingiram as maiores produções de grãos (Quadro 4). A variedade Carioca revelou-se o pior material em solução nutritiva; classificou-se, porém, entre as mais produtivas em campo. Catetão, a menos produtiva em campo, mostrou desempenho inferior tanto na produção de matéria seca de parte aérea quanto de raízes em solução nutritiva. Nitrodente, a segunda variedade mais produtiva, foi considerada a mais eficiente no ensaio de campo num suprimento adequado de $\mathrm{P}$ (Quadro 6), dentro dos critérios de eficiência de utilização empregados, confirmando a tendência apresentada em solução nutritiva.

Os resultados para Catetão, BR 105, BR 106, BR 107, Antigo Maya e Sol da Manhã também são comparáveis entre os experimentos de campo e casa de vegetação. Para as variedades locais Caiano e Carioca, os desempenhos foram bastante diferentes nas duas condições. Alguns estudos fisiológicos e morfológicos 
foram realizados nessas variedades, na tentativa de melhor compreender essas variações (MACHADO, 2000). A correspondência dos resultados foi significativa considerando que se trata de variedades de polinização aberta, de maior variabilidade e de menor estabilidade de suas características. As variedades melhoradas apresentaram, sobretudo, desempenho mais uniforme.

\section{CONCLUSÕES}

1. As variedades apresentaram variabilidade quanto aos índices de eficiência ao $\mathrm{P}$ em solução nutritiva e em campo.

2. Houve correspondência entre os resultados obtidos em campo e em solução nutritiva para a maioria das variedades, com exceção das variedades locais Caiano e Carioca.

3. As variedades melhoradas Nitrodente e BR 106 se apresentaram como as mais eficientes e produtivas, enquanto Catetão, variedade local, apresentou menor eficiência e rendimento, tanto em campo quanto em solução nutritiva.

\section{REFERÊNCIAS BIBLIOGRÁFICAS}

ALMEIDA, D.L.; SANTOS, G.A.; DE-POLLI, H.; et al. Manual de Adubação para o Estado do Rio de Janeiro. Itaguaí: Editora Universidade Rural, 1988. 171p. (Coleção Universidade Rural - Série Ciências Agrárias, 2)

ALVES, V.M.C.; NOVAIS, R.F.; OLIVEIRA, M.F.G.; SANT'ANNA, R. Cinética e translocação de fósforo em híbridos de milho. Pesquisa Agropecuária Brasileira, Brasília, v.33, n.7, p.1047-1052, 1998.

ALVES, V.M.C.; VASCONCELLOS, C.A.; PITTA, G.V.E.; MAGNAVACA, R. Seleção de genótipos de milho para eficiência ao fósforo. Pesquisa Agropecuária Brasileira, Brasília, v.23, n.10, p.1083-1090, 1988.

BALIGAR, V.C.; FAGERIA, N.K. Nutrient use efficiency in acid soils: nutrient management and plant use efficiency. In: MONIZ, A.C.; FURLANI, A.M.C.; R.E. SCHAFFERT; FAGERIA, N.K.; ROSOLEM, C.A.; CANTARELLA, H. (Eds.). Plant - Soil Interactions at Low pH. Campinas: Brazilian Soil Science Society, 1997. p.75-95.

BLAIR, G. Nutrient efficiency what do we really mean? In: RANDALL, P.J.; DELHAITZE, E.; RICHARDS, R.A.; MUNNS, R. (Eds.). Genetic Aspects of Plant Mineral Nutrition. Dordrecht: Kluwer Academic, 1993. p.205213. (Developments in Plant and Soil Sciences, 50)

BREEZE, V.G.; WILD, A; HOPPER, M.J.; JONES, L.H.P. The uptake of phosphate by plants from flowing nutrient solution. Journal of Experimental Botany, Oxford, v.33, n.157, p.1210-1221, 1984.
CIARELLI, D.M.; FURLANI, A.M.C.; DECHEN, A.R.; LIMA, M. Genetic variation among maize genotypes for phosphorus-uptake and phosphorus-use efficiency in nutrient solution. Journal of Plant Nutrition, New York, v.21, n.10, p.2219-2229, 1998.

CLARK, R.B. Mineral element concentrations of corn plant parts with age. Communications in Soil Science and Plant Analysis, New York, v.6, n.4, p.451-464, 1975.

CLARK, R.B. Nutrient solution growth of sorghum and corn in mineral nutrition studies. Journal of Plant $\mathrm{Nu}$ trition, New York, v.5, n.8, p.1039-1057, 1982.

EMBRAPA. Centro Nacional de Pesquisa de Solos (Rio de Janeiro, RJ). Manual de métodos de análise de solo. 2.ed.rev.atual. Rio de Janeiro: CNPS, 1997. 212p.

EMBRAPA. Centro Nacional de Pesquisa de Solos (Rio de Janeiro, RJ). Sistema brasileiro de classificação de solos. Brasília: Embrapa Produção de Informação; Rio de Janeiro: Embrapa Solos, 1999. 412p.

FAGERIA, N.K.; BALIGAR, V.C. Phosphorus-use efficiency by corn genotypes. Journal of Plant Nutrition, New York, v.20, n.10, p.1267-1277, 1997.

FEIL, B.; THIRAPORN, R.; STAMP, P. Can maize cultivars with low mineral concentrations in the grains help to reduce the need for fertilizers in third world countries? Plant and Soil, Dordrecht, v.146, p.227-231, 1992.

FÖHSE, D.; CLAASSEN, N.; JUNGK, A. Phosphorus efficiency of plants. I. External and internal $P$ requirement and P uptake efficiency of different plant species. Plant and Soil, Dordrecht, v.110, p.101-109, 1988.

FOX, R. H. Selection for phosphorus efficiency in corn. Communications in Soil Science and Plant Analysis, New York, v.9, n.1, p.13-37, 1978.

FURLANI, A.M.C.; BATAGLIA, O.C.; LIMA, M. Eficiência de linhagens de milho na absorção e utilização de fósforo em solução nutritiva. Bragantia, Campinas, v.44, n.1, p.129-147, 1985.

FURLANI, A.M.C.; CLARK, R.B.; ROSS, W.M.; MARANVILLE, J.W. Differential phosphorus uptake, distribution and efficiency by sorghum inbred parents and their hybrids. In: GABELMAN, H.W.; LOUGHMAN, B.C. (Eds.). Genetic Aspects of Plant Mineral Nutrition. Dordrecht: Martinus Nyhoff, 1987. p.287-298.

FURLANI, A.M.C.; FURLANI, P.R. Composição e pH de soluções nutritivas para estudos fisiológicos e seleção de plantas em condições nutricionais adversas. Campinas: Instituto Agronômico, 1988. 34p. (Instituto Agronômico Boletim, 121)

FURLANI, A.M.C.; LIMA, M.; NASS, L.L. Combining ability effects for P-efficiency characters in maize grown in low P nutrient solution. Maydica, Bergamo, v.43, p.169-174, 1998. 
GILL, M.A.; SALIM, R.M.; ZIA, M.S. Maize growth and uptake of phosphate and copper at different ambient phosphate concentrations. Soil Science and Plant Nutrition, Tokyo, v. 8, n.4, p.631-636, 1992.

GORSLINE, G.W.; BAKER, D.E. ; THOMAS, W.I. Accumulation of eleven elements by field corn (Zea mays L.). Pennsylvania State University Bulletin, Harrisburg, v.725, p.1-33, 1965.

GOURLEY, C.J.P.; ALLAN, D.L.; RUSSELE, M.P. Defining phosphorus efficiency in plants. Plant and Soil, Dordrecht, v.155/156, p.289-292, 1993.

GOURLEY, C.J.P.; ALLAN, D.L.; RUSSELE, M.P. Plant nutrient efficiency: A comparison of definitions asd suggested improvement. Plant and Soil, Dordrecht, v.158, p.29-37, 1994.

HORST, W.J.; ABDOU, M.; WIESLER. Genotypic differences in phosphorus efficiency of wheat. Plant and Soil, Dordrecht, v.155/156, p.293-296, 1993.

ISRAEL, D.W.; RUFTY Jr., T.W. Influence of phosphorus nutrition on phosphorus and nitrogen efficiences and associated physiological responses in soybean. Crop Science, Madison, v.28, p.954-960, 1988.

JONES, G.P.D.; JESSOP, R.S.; BLAIR, G.J. Alternative methods for the selection of phosphorus efficiency in wheat. Field Crops Research, Amsterdan, v.30, p.29-40, 1992.

LOUGHMAN, B.C.; ROBERTS, S.C.; GOODWIN-BAILEY, C.I. Varietal differences in physiological and biochemical responses to changes in the ionic environment. Plant and Soil, Dordrecht, v.72, p.45-259, 1983.

MACHADO, A.T.; MACHADO, C.T. de T.; FURLANI, P.R. Avaliação e caracterização de variedades locais de milho para condições adversas de ambiente. In: SOARES, A.C.; MACHADO, A.T.; SILVA, B.M.; WEID, von der, J.M. (Eds.). Milho crioulo: conservação e uso da biodiversidade. Rio de Janeiro: AS-PTA, 1998, p.151-178.

MACHADO, C.T. de T. Avaliação da eficiência de utilização de fósforo de variedades locais de milho (Zea mays L.). Itaguaí, 1995. 131p. Tese (Mestrado em Agronomia / Ciência do Solo) - Universidade Federal Rural do Rio de Janeiro.

MACHADO, C.T. de T. Caracterização de genótipos de milho quanto a parâmetros morfológicos, fisiológicos e microbiológicos associados à eficiência de absorção e uso de fósforo. Seropédica, 2000. 365p. Tese (Doutorado em Agronomia /Ciência do Solo) - Universidade Federal Rural do Rio de Janeiro.

MACHADO, C.T. de T.; GUERRA, J.G.M.; ALMEIDA, D.L. de; MACHADO, A.T. Variabilidade entre genótipos de milho para eficiência no uso de fósforo. Bragantia, Campinas, v.58, n.1, p.109-124, 1999.

MARSCHNER, H. Mineral nutrition of higher plants. London: Academic Press, 1995. 889p.

MOLL, R.H.; KAMPRATH, E.J.; JACKSON, W.A. Analysis and interpretation of factors which contribute to efficiency of nitrogen utilization. Agronomy Journal, Madison, v.74, n.3, p.562-564, 1982.

SCHJORRING, J.K.; JENSÉN, P. Phosphorus export from roots to shoots of barley buckwheat and rape seedlings with different $\mathrm{P}$ status. Physiologia Plantarum, Copenhagen, v.70, p.58-64, 1987.

SCHULTHESS, U.; FEIL, B.; JUTZI, S.C. Yield-independent variation in grain nitrogen and phosphorus concentration among ethiopian wheats. Agronomy Journal, Madison, v.89, p.497-506, 1997.

SIDDIQI, M.Y.; GLASS, A.D.M. Utilization Index: A modified approach to the estimations and comparison of nutrient utilization efficiency in plants. Journal of Plant Nutrition, New York, v.4, n.3, p.289-302, 1981. 